Original Research Article

\title{
Cost effectiveness analysis in the management of stroke in a tertiary care hospital
}

\author{
Gargi Dey*, Jyothi R., Girish K.
}

Department of Pharmacology,

Kempegowda Institute of

Medical Sciences, Bangalore,

Karnataka, India

Received: 09 September 2019

Accepted: 16 October 2019

*Correspondence to:

Dr. Gargi Dey,

Email: gargidey16@gmail.com

Copyright: (C) the author(s), publisher and licensee Medip Academy. This is an openaccess article distributed under the terms of the Creative Commons Attribution NonCommercial License, which permits unrestricted noncommercial use, distribution, and reproduction in any medium, provided the original work is properly cited.

\begin{abstract}
Background: Stroke has a high economic impact on the society especially in a developing country like India. In India health insurance doesn't cover all people leading to out of pocket expenditure. The objective of the present study was to study the cost of illness and outcome of stroke in a tertiary care hospital.

Methods: Direct medical and nonmedical costs were obtained after 28 days of follow-up. The outcome of the stroke was measured by modified Rankin scale (mRS).

Results: The mean age of the patients was $65.38 \pm 13.98$ years. Majority of the patients suffered from ischemic stroke and belonged to lower middle socioeconomic group. The mean cost of stroke was INR 39819. There was improvement in the $\mathrm{mRS}$ score after 28 days following treatment of acute stroke.

Conclusions: Direct medical costs forms major component of cost of stroke. Early management and hospital discharge can reduce the economic burden of stroke.
\end{abstract}

Keywords: Cost of illness, Stroke, Direct costs

\section{INTRODUCTION}

Stroke is the second most common leading cause of death and third most common cause of disability of disabilityadjusted life year. ${ }^{1}$ It possesses a high socio-economic burden on the society especially the middle and lower economic group. However, there are few studies on the economic impact of stroke. The health insurance system in India varies from other countries especially for the older age group. ${ }^{2}$ In India, there are many bottlenecks in accessing the government health services, leading to high out of pocket expenditures in seeking private care. ${ }^{2}$ Pharmacoeconomics is the analysis of cost of drug therapy to healthcare systems and society. ${ }^{3}$ The objectives of the study are to study the cost of illness of stroke that is direct medical and nonmedical costs and to estimate the outcome of stroke.

\section{METHODS}

This was a prospective study carried out in the department of medicine of a tertiary care hospital in South India from December 2018 to August 2019. A sample size of 63 was calculated considering the prevalence of stroke as $1.9 \% .^{4}$ The study was approved by the institutional ethics committee. Clinical Trials Registry- India (CTRI) acknowledgment number is CTRI/2018/12/016683. Written informed consent was taken from the study subject/legal representatives of all the study subjects (in case patient was not in a position to respond).

\section{Inclusion criteria}

The study subjects of either gender aged $>18$ years with acute stroke of vascular origin diagnosed and confirmed 
by radiological investigations and patients with recurrent stroke were included.

\section{Exclusions criteria}

Old cases of stroke admitted for co-morbidities and patients with neurological deficit due to other causes were excluded.

Baseline demographic data was taken. The cost related data included direct medical and nonmedical costs. The indirect costs and intangible costs were not estimated. The direct cost was calculated as direct medical costs which include costs of hospitalisation, investigations including laboratory and radiological, drugs, physiotherapy, doctors referral. The direct nonmedical costs such as transportation expenditure for both the subjects and caregivers was calculated. The costs were calculated based on the information provided by the patients and/or their caregivers. The outcome of therapy was assessed using modified Rankin Scale (mRS). The $\mathrm{mRS}$ ranges from 0 to 6 is the most widely used scale to measure stroke outcome. The costs and outcome of the therapy were assessed after 28 days of admission. If the patient was discharged before 28 days, the outcome was assessed through personal telephonic enquiry.

\section{Statistical analysis}

The statistical analysis was performed using MS Excel 2013 spreadsheet. Descriptive statistics namely mean, percentage and standard deviation were used for quantitative variables. Paired t-test was used to compare the mRS at the admission and after 28 days of treatment for stroke. $\mathrm{P}$ value $<0.05$ was considered significant in the two tailed analysis.

\section{RESULTS}

70 patients were enrolled in the study out of which 50 were included who gave complete information and followed up after 28 days.

Table 1 shows the baseline characteristics of the patients. Of the total patients $33(66 \%)$ were males and $17(34 \%)$ were females. Majority of the patients belonged to lower middle group of socioeconomic status 28 (56\%).

Table 1: Baseline characteristics.

\begin{tabular}{|ll|}
\hline Variables & $\mathbf{N}(\%)$ \\
\hline Gender & $33(66)$ \\
\hline Men & $17(34)$ \\
\hline Women & $4(8)$ \\
\hline Socioeconomic status* & $17(34)$ \\
\hline Upper & $28(56)$ \\
\hline Upper middle & $1(2)$ \\
\hline Lower middle & 0 \\
\hline Upper lower & \\
\hline Lower & $29(58)$ \\
\hline Type of stroke & $21(42)$ \\
\hline Ischemic & \\
\hline Haemorrhagic & $34(68)$ \\
\hline Co-morbidities & $26(52)$ \\
\hline Hypertension & $5(10)$ \\
\hline Diabetes mellitus & $4(8)$ \\
\hline Ischemic heart disease & \\
\hline Others & \\
\hline *Based on Kuppuswamy socioeconomic status scale (modified for 2007); \\
§: Chronic obstructive pulmonary disease, hypothyroidism, benign prostatic hyperplasia etc. \\
\hline
\end{tabular}

Table 2: Direct medical and nonmedical cost at 28 days of follow up.

\begin{tabular}{|ll|}
\hline \hline Variables & Mean \pm S.D \\
\hline Direct medical cost (in INR) & \\
\hline Hospitalisation costs & $35660 \pm 13855$ \\
\hline Total drugs costs & $3099 \pm 204$ \\
\hline Outpatient department charges & $25 \pm 8$ \\
\hline Direct non-medical cost (in INR) & $581 \pm 134$ \\
\hline Travel costs & $454 \pm 128$ \\
\hline Other expenditures & \\
\hline
\end{tabular}


Table 3: Mean change in outcome after 28 days.

\begin{tabular}{|llll|}
\hline Change in mRS score & Day 0 & Day 28 & P value \\
\hline mRS score & $3.48 \pm 1.33$ & $2.61 \pm 1.9$ & 0.24 \\
\hline
\end{tabular}

Ischemic stroke $29(58 \%)$ constituted majority of stroke than haemorrhagic 21 (42\%). Most common comorbidities were hypertension $34(68 \%)$ and diabetes mellitus $26(52 \%)$. Patients also had more than one comorbidities. The mean age of the patients was $65.38 \pm 13.98$ years. The average length of hospital stay was $14.9 \pm 5.1$ days.

Table 2 depicts the direct medical and nonmedical costs. The direct medical costs which include hospitalisation, drugs and outpatient department costs about INR 38784. The direct non-medical cost which is the travel and other expenditure costs of the patients and caregivers was about INR 1035.

Table 3 shows the outcome of stroke. There is decline in the mRS score over 28 days which favours the outcome though the difference is not significant.

\section{DISCUSSION}

Stroke is found to be more common in males $(66 \%)$ than females $(34 \%)$. This stands similar to the by Himaja et al in which $71.4 \%$ were males and $28.6 \%$ females. ${ }^{5}$ The male preponderance can be due to the reason that in developing countries like India males seek more medical attention than females due to low socioeconomic status, cultural restraints, social deprivation etc. ${ }^{6}$ This can also be due to prevalence of risk factors like smoking and drinking are more common in India in men. Majority of the patients belong to lower middle class $(56 \%)$. This is in line with the study in India by Sharma et al which showed $90 \%$ of the patients belonged to lower socioeconomic class. ${ }^{7}$ Study by Kumar et al also suggested that low economic status was independently associated with the risk of ischemic stroke in North India. ${ }^{8}$ Our study findings of prevalence of ischemic stroke $(58 \%)$ more than haemorrhagic $(42 \%)$ is in similar line with study by Mudhaliar et al; ischemic stroke $65.56 \%$ and haemorrhagic stroke $32.22 \%$. $^{4}$ The mean age of 65.38 years suggests prevalence of stroke in the older age group. The average hospital stay was $14.9 \pm 5.1$ days. One of the factors of short hospital stay is early discharge requested by the patients/caregivers who can afford the inpatient costs or loss of wages since the hospital being a private teaching hospital in a metro city.

In our study the overall cost of stroke is INR 39819 mainly contributed by the direct medical costs. This study showed the cost of 1 month whereas other studies in India ${ }^{2}$ and other Asian countries like Japan and Taiwan had longer follow up. ${ }^{9,10}$ Patients who stayed for longer period of time $>10$ days due to poor prognosis had higher cost. This includes intensive care unit charges in addition to routine services charges.

The cost of stroke can be saved by adopting home-based rehabilitation especially for people from rural areas who do not have easy access to tertiary care hospitals. ${ }^{11}$ Study by Kwatra et al also concluded that home-based rehabilitation can reduce the length of hospital stay and hence the cost. ${ }^{2}$ Reducing the stay in hospital by empirical antibiotic therapy (which was given in our hospital) to prevent infections, cutting down on unnecessary tests and efficient diagnosis of stroke can reduce the acute care cost. ${ }^{12}$

The improvement in mRS over 1 month suggests relative feasibility in the management of stroke. With early intervention by drug therapy and physical rehabilitation, regular follow up the economic burden of the stroke can be reduced. ${ }^{13}$

\section{Strength}

The study provides short term cost for management of acute stroke.

\section{Limitation}

Since stroke is a chronic neurological disease and requires permanent dependence long term follow up for at least 3 months is required.

\section{CONCLUSION}

Direct medical cost has a major impact on the overall cost of the stroke. Majority of the burden falls on the lower income group of patients. Early management and rehabilitation can reduce the length of stay, therefore the cost of stroke.

Funding: No funding sources

Conflict of interest: None declared

Ethical approval: The study was approved by the Institutional Ethics Committee

\section{REFERENCES}

1. Feigi VL, Norrving B, Mensah GA. Global Burden of Stroke. 2017;120:439-48.

2. Kwatra G, Kaur P, Toor G, Badyal DK, Kaur R, Singh Y, et al. Cost of stroke from a tertiary center in northwest India. Neurol India. 2013;61(1):627-32.

3. Powar PV, Nagare A, Ambikar RB, Sharma PH, Vyawahare NS. Pharmacoeconomics- costs of drug 
therapy to healthcare systems. J Modern Drug Discovery Drud Delivery Res. 2014;1(2):2348-3776.

4. Mudhaliar MR, Swarnakumari D, Yiragamreddy PR, Venkataramana B. Drug evaluation and appropriateness of medication used in stroke patients. WJPMR. 2016;2(5):168-74.

5. Himaja J, Rakesh B. A study of clinical profile, risk factors and drug utilisation pattern in cerebrovascular stroke. Eur J Biomed Pharm Sci. 2017;4:258-73.

6. Miah MN, Azhar MA, Rahman A, Haldar D, Akteruzzaman M, Kundu NC. Risk factors of stroke in young and old age group- a comparative study. J Med. 2012;13:138-42.

7. Sharma M, Lal M, Singh T, Deepti SS. Factors associated with physical and psychosocial problems among Indian stroke survivors. Indian J Palliative Care. 2019;25(1):18-23.

8. Kumar A, Prasad M, Kathuria P, Nair P, Pandit AK, Sahu JK, et al. Low socioeconomic status is an independent risk factor for ischemic stroke: a casecontrol study in North Indian population. Neuroepidemiol. 2015;44:138-43.

9. Yoneda Y, Uehara T, Yamasaki H, Kita Y, Tabuchi M, Mori E. Hospital-based study of the care and cost of acute ischemic stroke in Japan. Stroke. 2003;34:718-24.
10. Chang KC, Lee HC, Huang YC, Hung JW, Chiu HE, Chen JJ, et al. Cost-effectiveness analysis of stroke management under a universal health insurance system. J Neurol Sci 2012;323(1-2):205-15.

11. Housley SN, Garlow AR, Ducote K, Howard A, Thomas $\mathrm{T}, \mathrm{Wu} \mathrm{D}$, et al. Increasing access to cost effective home-based rehabilitation for rural veteran stroke survivors. Aus J Cerebrovas Dis Stroke. 2016;3(2):1-11.

12. Many routinely prescribed treatments for stroke patients are costly are not supported solid evidence according to investigators. Can Clincians reduce inhospital care costs for stroke patients?. Neurology Reviews. 2012;20(10): 17.

13. Dey G, Jyothi R, Kumar BNP, Girish K. A retrospective observational study of the effect of physiotherapy treatment on outcomes in stroke patients. Natl J Physiol Pharm Pharmacol. 2019;9(8):780-3.

Cite this article as: Dey G, Jyothi R, Girish K. Cost effectiveness analysis in the management of stroke in a tertiary care hospital. Int J Basic Clin Pharmacol 2019;8:2566-9. 